\title{
Implementasi metode Simple Multi Attribute Rating Technique untuk penentuan prioritas rehabilitasi dan rekonstruksi pascabencana alam
}

\author{
Saifur Rohman Cholil a, Agusta Praba Ristadi Pinem b, Vensy Vydia c \\ $a, b, c$ Sistem Informasi, Universitas Semarang, Semarang \\ email:acholil@usm.ac.id, bagusta.pinem@usm.ac.id, cvensy@usm.ac.id
}

\begin{tabular}{l}
\hline I N F O A R T I K E L \\
\hline Sejarah artikel: \\
Menerima 19 April 2018 \\
Revisi 27 Juli 2018 \\
Diterima 27 Juli 2018 \\
Online 27 Juli 2018 \\
\hline
\end{tabular}

\section{Kata kunci:}

bencana

rehabilitasi

rekonstruksi

SMART

SPK

\section{Keywords: \\ Decision Support System disaster \\ rehab \\ reconstruct \\ SMART}

Style APA dalam mensitasi artikel ini:

Cholil, S. R., Pinem, A. P., \& Vydia, V. (2018).

Implementasi metode Simple Multi Attribute Rating

Technique untuk penentuan prioritas rehabilitasi dan rekonstruksi pascabencana alam. Register: Jurnal Ilmiah Teknologi Sistem Informasi, 4(1), 1-6.

\begin{abstract}
ABSTRAK
Penanganan bencana alam di Indonesia menjadi hal yang sangat penting untuk segera dilakukan dalam menentukan prioritas rehabilitasi dan rekonstruksi wilayah pascabencana alam. Penentuan prioritas rehabilitasi dan rekonstruksi pascabencana alam dilakukan dengan pendekatan metodologi Sistem Pendukung Keputusan (SPK) untuk membantu menyelesaikan permasalahan dalam proses pengambilan keputusan. Metode Simple Multi Attribute Rating Technique (SMART) akan diterapkan untuk menentukan prioritas wilayah pada rencana aksi rehabilitasi dan rekonstruksi pascabencana alam karena kesederhanaannya pada proses perhitungan dalam pemilihan alternatif yang telah dirumuskan. Tujuan penelitian ini adalah menghasilkan SPK dengan mengimplementasikan metode SMART untuk menentukan prioritas rehabilitasi dan rekonstruksi wilayah pascabencana, sehingga proses penanggulangan bencana akan tepat sasaran dan sesuai dengan peraturan penanggulangan bencana alam. Proses validasi pada penelitian ini adalah dengan membandingkan hasil metode dengan data fakta atau data kejadian (data histori). Koefisien Korelasi Rank Spearman yang diperoleh yaitu 0,95 . Hal ini menunjukan bahwa, metode SMART bisa digunakan untuk menentukan prioritas rehabilitasi dan rekonstruksi pascabencana alam.
\end{abstract}

\section{ABSTRACT}

The handling of natural disasters in Indonesia becomes a very important thing to be done in determining the priority of rehabilitation and reconstruction of post-disaster natural areas. The prioritization of post-disaster natural rehabilitation and reconstruction is done by methodology of Decision Support System (DSS) to help solve problems in decision making process. The Simple Multi Attribute Rating Technique (SMART) method will be applied to determine the priority of the region in the post-disaster natural rehabilitation and reconstruction action plan because of its simplicity in the calculation process in the alternative selection that has been formulated. The purpose of this research is to produce SPK by implementing SMART method to determine priority of rehabilitation and reconstruction of post disaster area, so that disaster management process will be appropriate target and in accordance with natural disaster management regulation. The validation process in this research is by comparing the method result with fact data or event data (historical data). Spearman Rank Correlation Coefficient obtained is 0.95. This indicates that the SMART method can be used to determine priorities for post-disaster rehabilitation and reconstruction.

๑ 2018 Register: Jurnal Ilmiah Teknologi Sistem Informasi. Semua hak cipta dilindungi undang-undang.

\section{Pendahuluan}

Negara Indonesia adalah negara kepulauan yang rawan akan bencana alam. Wilayah Indonesia dengan geologinya menyebabkan kejadian bencana alam tsunami Aceh, gempa bumi Yogyakarta, meletusnya Gunung Merapi, serta beberapa bencana lain sebelum dan sesudahnya yang telah membuat bangsa 
Indonesia untuk tanggap terhadap bencana alam (BNPB, 2011). Hal tersebut mendorong negara Indonesia cepat tanggap dalam menangani dan menanggulangi bencana alam. Beberapa diantaranya adalah dibentuknya Badan Nasional Penanggulangan Bencana (BNPB), undang-undang, serta peraturan pemerintah. Beberapa tugas BNPB diantaranya adalah menentukan Rencana Aksi Nasional Rehabilitasi dan Rekonstruksi (Renaksi RR) wilayah pascakejadian bencana alam (Kurniawan, Yunus, Amri, \& Pramudiarta, 2011). Penentuan prioritas Rencana Aksi Nasional (Renaksi) wilayah setelah bencana alam merupakan salah satu tugas dari BNPB.

Sistem Pendukung Keputusan (SPK) merupakan suatu pendekatan atau metodologi untuk mendukung proses pengambilan keputusan dengan menentukan alternatif dan kriteria (Sholikhah, Satyareni, \& Anugerah, 2016). Penelitian yang menggunakan SPK diantaranya digunakan untuk menentukan konsentrasi bidang keilmuan mahasiswa yang akan mengambil tugas akhir (Khoirudin, Abdillah, \& Cholil, 2018) dan untuk penentuan pemberian kredit kedua pada koperasi simpan pinjam (Pinem, Pungkasanti, \& Widodo, 2017). Metode Simple Multi Attribute Rating Technique (SMART) merupakan metode pengambilan keputusan multiatribut yang digunakan untuk mendukung pembuat keputusan dalam memilih antara beberapa alternatif (Nofriansyah \& Defit, 2017). Beberapa penelitian yang menggunakan metode SMART dalam SPK untuk pemilihan karyawan teladan (Suryanto \& Safrizal, 2015), penentuan kelayakan bisnis (Diana, 2016), metode SMART juga digunakan untuk rekomendasi pembelian grosir pada toko mainan (Sanjaya, Khairina, \& Maharani, 2015), pengukuran kinerja karyawan pada sebuah perusahaan (Kasie, 2013), dan penerapan teknologi terbaru tenaga listrik untuk menjalankan generator (Taylor Jr \& Love, 2014).

\section{State of the Art}

\subsection{Penanggulangan bencana alam}

Secara garis besar, tugas BNPB adalah menanggulangi kejadian bencana alam. Proses penanggulangan bencana dilakukan dengan Rencana Aksi Rehabilitasi dan Rekonstruksi (Renaksi RR) wilayah pascakejadian bencana alam (Kurniawan, Yunus, Amri, \& Pramudiantara, 2011). Rehabilitasi merupakan langkah perbaikan dan pemulihan semua sektor menyangkut pelayanan publik atau masyarakat, sedangkan rekonstruksi adalah proses pembangunan kembali prasarana dan sarana pada wilayah terdampak, baik pada tingkat pemerintahan maupun masyarakat (BNPB, 2011). Dalam merumuskan Renaksi RR menggunakan beberapa komponen yang mengacu pada aspek fisik dan aspek kemanusiaan, yaitu Damages and Losses Assessment (DaLA) atau Penilaian Kerusakan dan Kerugian, Human Recovery Need Assesment (HRNA) atau Pengkajian Kebutuhan Pemulihan Manusia. DaLA dan HRNA dikelompokkan dalam beberapa aspek atau sektor yang terkena dampak pascabencana alam. Aspek yang diteliti mencangkup aspek utama pada proses rehabilitasi dan rekonstruksi pascabencana, yaitu aspek kemanusiaan, perumahan, infrastruktur, ekonomi, sosial dan lintas sektor (BNPB, 2011), seperti yang ditampilkan pada Tabel 1.

\subsection{Simple Multi Attribute Rating Technique (SMART)}

Tabel 1. Estimasi akibat bencana alam (BNPB, 2011)

\begin{tabular}{clcl}
\hline \multicolumn{1}{c}{ Sektor } & \multicolumn{1}{c}{ Sub Sektor } & Satuan & \multicolumn{1}{c}{ Nilai Kerusakan } \\
\hline \multirow{2}{*}{ Kemanusiaan } & Korban & Jiwa & - \\
\multirow{2}{*}{ Perumahan } & Populasi & Jiwa & - \\
& Perumahan & Unit & Jml nilai rusak $\times$ harga satuan \\
& Jalan & Km & Jalan rusak per km $\times$ harga satuan \\
Infrastuktur & Sungai & $\mathrm{m}$ & Sungai rusak per $\mathrm{m} \times$ harga satuan \\
& Energi & Unit & Kerusakan unit $\times$ harga satuan \\
& Air dan sanitasi & Unit & Kerusakan unit infrastuktur PDAM $\times$ harga satuan \\
\multirow{5}{*}{ Sosial } & Tempat ibadah & Unit & Kerusakan bangunan $\times$ harga satuan \\
& Kesehatan & Unit & Kerusakan bangunan kesehatan $\times$ harga satuan \\
& Panti sosial & Unit & Kerusakan bangunan $\times$ harga satuan \\
Ekonomi & Pertanian & Ha & Kerusakan lahan pertanian $\times$ harga satuan hektar \\
& Perikanan & Unit & Kerusakan kolam budidaya ikan $\times$ harga satuan \\
Lintas sektor & UKM & Unit & Kerusakan bangunan $\times$ harga satuan \\
& Pemerintahan & Unit & Kerusakan bangunan $\times$ harga satuan \\
& Keamanan & Unit & Kerusakan bangunan $\times$ harga satuan \\
\hline
\end{tabular}


Metode SMART termasuk pada DSS dengan multiple criteria decision making, yaitu metode pengambilan keputusan yang didasarkan setiap alternatif terdiri dari sejumlah kriteria yang memiliki nilai dan bobot, di mana bobot menunjukan seberapa penting kriteria satu dengan kriteria lain (Suryanto \& Safrizal, 2015). Pemberian nilai bobot masing-masing kriteria pada metode SMART dilakukan dengan menggunakan skala 1-100. Proses pembobotan dan penilaian pada metode ini diberikan oleh perusahaan atau seorang yang berhak mengambil keputusan atas objek yang diteliti (Yunitarini, 2013).

\section{Metode Penelitian}

Tahapan yang dilalui dalam metode SMART yang ditunjukkan pada Gambar 1.

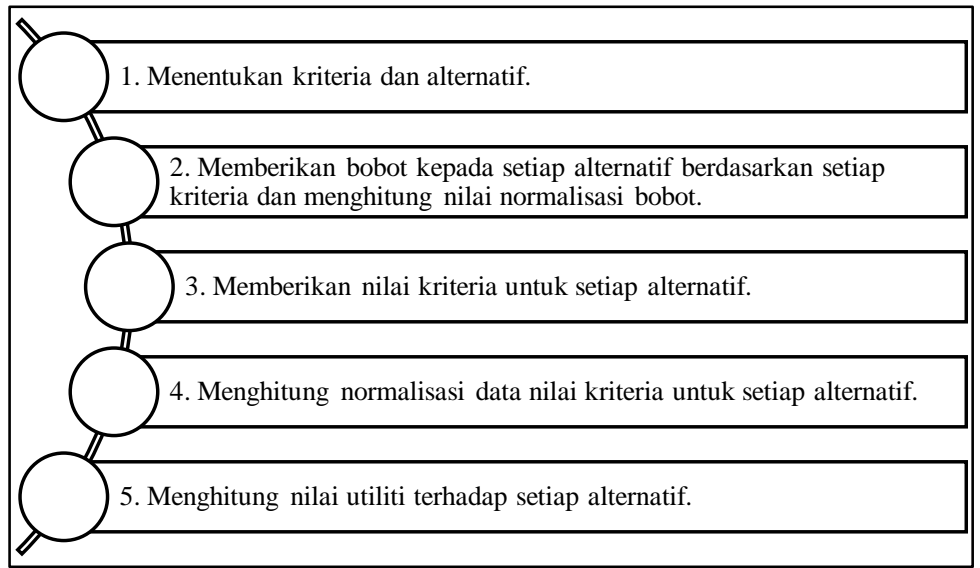

Gambar 1. Tahapan metode SMART

1. Menentukan kriteria dan alternatif yang digunakan dalam menyelesaikan masalah pengambilan keputusan.

2. Memberikan bobot pada masing-masing kriteria menggunakan skala 1-100 dengan memperhatikan prioritas terpenting. Selanjutnya menghitung normalisasi dari setiap kriteria dengan membandingkan nilai bobot kriteria dengan jumlah bobot kriteria, menggunakan Persamaan 1,

Normalisasi $=\frac{w_{j}}{\sum_{j=1}^{m} w_{m}}$

di mana $w j$ adalah nilai bobot kriteria ke-j, $m$ adalah jumlah kriteria, dan $w m$ adalah bobot kriteria ke-m.

3. Memberikan nilai kriteria untuk setiap alternatif, nilai kriteria untuk setiap alternatif ini dapat berbentuk data kuantitatif (angka) ataupun berbentuk data kualitatif. Misalkan nilai untuk kriteria jumlah sudah dapat dipastikan berbentuk kuantitatif, sedangkan nilai untuk kriteria fasilitas berbentuk kualitatif (sangat lengkap, lengkap, kurang lengkap). Apabila nilai kriteria berbetuk kualitatif, maka dilakukan perubahan ke data kuantitatif dengan membuat parameter nilai kriteria, misalkan sangat lengkap artinya 3, lengkap artinya 2 dan kurang lengkap artinya 1.

4. Menghitung normalisasi data nilai kriteria untuk setiap alternatif. Proses normalisasi diperlukan untuk mengubah nilai data dalam satuan jiwa dan rupiah menjadi comparable (sebanding). Normalisasi data dapat dilakukan dengan menggunakan Persamaan 2,

$R_{i j}=\frac{x_{i j}}{\sqrt{\sum_{i=1}^{m} x_{i j}^{2}}}$

untuk $1,2,3, \ldots . . m$ dan $j=1,2,3, \ldots . . . n$. Selanjutnya mencari nilai rata-rata nilai dengan menggunakan rata-rata geometrik untuk memberikan kemudahan dan konsistensi dalam mengambil nilai dari himpunan dengan Persamaan 3,

$G=\sqrt[n]{x_{1} \cdot x_{2} \cdot x_{3} \ldots x_{n}}$

di mana $n$ adalah jumlah sub kriteria dalam satu kriteria, $x$ adalah nilai. Kemudian diperoleh matrik $R$ hasil normalisasi dan rata-rata dari sub kriteria yang membentuk perbandingan berpasangan setiap alternatif pada masing-masing kriteria, dengan Persamaan 4, 


$$
R=\left[\begin{array}{lll}
r_{11} & r_{12} & r_{1 j} \\
r_{21} & r_{22} & r_{2 j} \\
r_{i 1} & r_{i 2} & r_{i j}
\end{array}\right]
$$

5. Menentukan nilai utility dengan mengkonversikan nilai kriteria pada masing-masing kriteria menjadi nilai kriteria data baku. Nilai kriteria ini bergantung pada sifat kriteria itu sendiri.

Kriteria yang termasuk kategori keuntungan (benefit) dihitung menggunakan Persamaan 5,

$$
\text { ui(ai) }=\left(\frac{c_{\text {out }}-c_{\min }}{c_{\max }-c_{\min }}\right) \times 100 \%
$$

di mana ui (ai) adalah nilai utility kriteria ke $i$, cmax adalah nilai kriteria maksimal, cmin adalah nilai kriteria minimal, cout adalah nilai kriteria ke $i$. Kriteria yang termasuk kategori biaya (cost) dihitung menggunakan Persamaan 6,

ui(ai) $=\left(\frac{c_{\max }-c_{\text {out }}}{c_{\max }-c_{\min }}\right) \times 100 \%$

Selanjutnya menentukan nilai akhir dengan mengalikan angka yang didapat dari normalisasi nilai kriteria data baku dengan nilai normalisasi bobot kriteria dan menjumlahkan nilai dari perkalian tersebut, seperti pada Persamaan 7 ,

$\mathrm{u}(\mathrm{ai})=\sum_{j=1}^{m} w_{j} u_{i}\left(a_{i}\right)$

di mana $u(a i)$ adalah nilai total alternatif, wj adalah hasil dari normalisasi bobot kriteria, ui(ai) adalah hasil penentuan nilai utility.

\section{Hasil dan Pembahasan}

Tabel 2 adalah hasil dari implementasi sistem memperlihatkan bahwa kabupaten Klaten dan Bantul merupakan alternatif terbaik untuk setiap provinsi Jawa Tengah dan Daerah Istimewa Yogyakarta (DIY). Kabupaten Klaten memiliki nilai utility 0,79, sedangkan kabupaten Bantul nilai utility 0,74.

Tabel 2. Prioritas rehabilitasi dan rekonstruksi

\begin{tabular}{clcl}
\hline Prioritas & \multicolumn{1}{c}{ Alternatif } & Nilai Akhir & \multicolumn{1}{c}{ Propinsi } \\
\hline 1 & A1 (Klaten) & 0,799 & Jawa Tengah \\
2 & A3 (Boyolali) & $0,024)$ & Jawa Tengah \\
3 & A4 (Sukoharjo) & 0,013 & Jawa Tengah \\
4 & A5 (Wonogiri) & 0,012 & Jawa Tengah \\
5 & A2 (Magelang) & 0,008 & Jawa Tengah \\
6 & A6 (Purworejo) & 0,001 & Jawa Tengah \\
\hline 1 & A7 (Bantul) & 0,742 & DIY \\
2 & A8 (Sleman) & 0,239 & DIY \\
3 & A11 (Gunung Kidul) & 0,189 & DIY \\
4 & A9 (Yogyakarta) & 0,188 & DIY \\
5 & A10 (Kulonprogo) & 0,124 & DIY \\
\hline
\end{tabular}

Tabel 3. Validasi dengan korelasi Rank Spearman

\begin{tabular}{clcccc}
\hline \multicolumn{1}{c}{ Propinsi } & Kabupaten & Alternatif & Utility & Ranking & Histori \\
\hline Jawa Tengah & Klaten & A1 & 0,799 & 1 & 1 \\
Jawa Tengah & Magelang & A2 & 0,008 & 5 & 5 \\
Jawa Tengah & Boyolali & A3 & 0,024 & 2 & 2 \\
Jawa Tengah & Sukoharjo & A4 & 0,013 & 3 & 4 \\
Jawa Tengah & Wonogiri & A5 & 0,012 & 4 & 3 \\
Jawa Tengah & Purworejo & A6 & 0,001 & 6 & 6 \\
Yogyakarta & Bantul & A7 & 0,742 & 1 & 1 \\
Yogyakarta & Sleman & A8 & 0,239 & 2 & 2 \\
Yogyakarta & Yogyakarta & A9 & 0,188 & 4 & 5 \\
Yogyakarta & Kulonprogo & A10 & 0,124 & 5 & 3 \\
Yogyakarta & Gunung & A11 & 0,189 & 3 & 5 \\
\hline
\end{tabular}


Proses validasi adalah proses membandingkan hasil metode dengan data fakta/kejadian yang disebut sebagai data histori. Penelitian ini menggunakan kasus data kejadian gempa Yogyakarta pada tahun 2006. Proses perhitungan baik pada sistem maupun perhitungan manual akan dibandingkan dengan dokumen Renaksi yang dikeluarkan oleh BNPB dan BAPPEDA (Badan Perencanaan Pembangunan Daerah). Dokumen Renaksi RR adalah dokumen susunan rencana penanggulangan bencana alam pada daerah terdampak dengan mengacu pada DaLA dan HRNA.

Metode SMART menghasilkan peringkat prioritas penanganan, output tersebut dibandingkan dengan prioritas penanganan dari dokumentasi BNPB dan BAPPEDA dalam Renaksi. Proses validasi menggunakan korelasi Rank Spearman untuk mencari nilai keterkaitan output sistem dengan data histori.

Koefisien korelasi Rank Spearman yang diperoleh yaitu 0,95 seperti pada Tabel 3. Hal ini menunjukan bahwa peringkat prioritasi penanganan bencana yang dihasilkan oleh metode SMART telah sesuai dengan prioritas dokumen Renaksi yang dikeluarkan oleh BAPPEDA Jawa Tengah dan DIY. Nilai koefisien korelasi Rank Spearman dikatakan sempurna apabila mendekati nilai 1. Selain itu, prioritas utama setiap provinsi Jawa Tengah dan Daerah Istimewa Yogyakarta menunjukan kesesuaian antara dokumen Renaksi dan metode SMART, di mana kabupaten Klaten dan Bantul merupakan prioritas utama setiap provinsi Jawa Tengah dan Daerah Istimewa Yogyakarta, baik pada dokumentasi Renaksi maupun metode SMART.

\section{Kesimpulan}

Penelitian ini telah berhasil dilakukan sesuai dengan usulan, yaitu implementasi metode SMART untuk penentuan prioritas rehabilitasi dan rekonstruksi wilayah pascabencana alam di propinsi Jawa Tengah dan DIY. Hal ini dapat dilihat dari hasil pengujian dan verifikasi yang memiliki nilai sama, dengan membandingkan data fakta/ kejadian dari BPBD dengan koefisien korelasi Rank Spearman sebesar 0,95. Hal ini menunjukan bahwa metode SMART bisa digunakan untuk menentukan prioritas rehabilitasi dan rekonstruksi pascabencana alam. Saran untuk penelitian selanjutnya adalah membandingkan metode SMART dengan metode yang lain, terutama dalam proses penentuan bobot pada pengambilan keputusan multikriteria.

\section{Ucapan Terima Kasih}

Ucapan terima kasih kepada Lembaga Penelitian dan Pengabdian Masyarakat (LPPM) Universitas Semarang atas sumber dana penelitian dengan nomor kontrak: 298/USM.H9/L/2017.

\section{Referensi}

BNPB. (2011). Peraturan Kepala Badan Nasional Penanggulangan Bencana Nomor 6.A Tahun 2011. Jakarta, DKI Jakarta, Indonesia. Retrieved from https://bnpb.go.id/uploads/migration/pubs/40.pdf BNPB. (2011). Rencana Aksi Rehabilitasi dan Rekonstruksi Wilayah Pascabencana Erupsi Gunung Merapi di Provinsi D.I. Yogyakarta dan Provinsi Jawa Tengah Tahun 2011-2013. Jakarta: BAPPENAS \& BNPB. Retrieved from https://www.bnpb.go.id/rencana-aksi-rehabilitasi-dan-rekonstruksi-wilayahpascabencana-erupsi-gunung-merapi-di-prov-diy-dan-prov-jateng-tahun-2011-2013

Diana, D. (2016). Sistem Pendukung Keputusan Menentukan Kelayakan Bisnis Menggunakan Simple Multi Attribute Rating Technique (SMART). Matrik, 18(2), 1411-1624.

Kasie, F. M. (2013). Combining Simple Multiple Attribute Rating Technique and Analytical Hierarchy Process for Designing Multi-criteria Performance Measurement Framework. The Global Journal of Researches in Engineering, 13(1), 16-24.

Khoirudin, K., Abdillah, M. Z., \& Cholil, S. R. (2018). Concentration Determination Disciplines Of Final Projects Using Simple Additive Weighting. Jurnal Informatika, 15(2), 74-85.

Kurniawan, L., Yunus, R., Amri, M. R., \& Pramudiantara, N. (2011). Indeks rawan bencana indonesia. Jakarta: BNPB.

Nofriansyah, D., \& Defit, S. (2017). Multi Criteria Decision Making (MCDM) pada Sistem Pendukung Keputusan. Yogyakarta: Deepublish Publisher.

Pinem, A. P., Pungkasanti, P. T., \& Widodo, E. (2017). Implementasi Profile Matching untuk pemberian kredit kedua pada koperasi simpan pinjam. Simetris, 8(2), 539-546. 
Sanjaya, A., Khairina, D. M., \& Maharani, S. (2015). Rekomendasi pembelian grosir pada toko mainan menggunakan metode Simple Multi Attribute Rating Technique (SMART) dengan Google Maps. Prosiding Seminar Sains dan Teknologi (pp. 1-5). Samarinda: FMIPA - Universitas Mulawarman.

Sholikhah, F., Satyareni, D. H., \& Anugerah, C. S. (2016). Perancangan Sistem Pendukung Keputusan Pemilihan Pelanggan Terbaik Menggunakan Metode Simple Additive Weighting (SAW) Pada Bravo Supermarket Jombang. Register: Jurnal Ilmiah Teknologi Sistem Informasi, 2(1), 40-50.

Suryanto, S., \& Safrizal, M. (2015). Sistem Pendukung Keputusan Pemilihan Karyawan Teladan denganMetode SMART (Simple Multi Attribute Rating Technique). Jurnal CorelT, 1(1), 25-29.

Taylor Jr, J., \& Love, B. N. (2014). Simple multi-attribute rating technique for renewable energy deployment decisions (SMART REDD). The Journal of Defense Modeling and Simulation, 11(3), 227232.

Yunitarini, R. (2013). Sistem Pendukung Keputusan Pemilihan Penyiar Radio Terbaik. Jurnal Ilmiah Mikrotek, 1(1), 43-52. 